\title{
Optical properties of dielectric layers with $\mathrm{CeO}_{2}$
}

\author{
T.V. Semikina \\ Department of Environmental \& Material Engineering, Teikyo University of Science \& Technology, \\ 2525 Yatsusawa, Uenohara-machi, Kitatsuru-gun, Yamanashi-pref., 409-0193 Japan, \\ E-mail: semikina@edd.ntu-kpi.kiev.ua,tanyasemikina@rambler.ru
}

\begin{abstract}
The polycrystalline thin films $\mathrm{CeO}_{2}, \mathrm{WO}_{3}$, amorphous complex films $\mathrm{WO}_{3}+\mathrm{CeO}_{2}$ with content of $\mathrm{CeO}_{2}$ in the powder 10,15 and $20 \%$, and $\mathrm{CeO}_{2}+\mathrm{Dy}_{2} \mathrm{O}_{3}$ with content of $\mathrm{Dy}_{2} \mathrm{O}_{3}$ in the powder 10,15 and $20 \%$ are obtained by vacuum deposition method via powder evaporation. For the first time the optical characteristics of complex films $\mathrm{WO}_{3}+\mathrm{CeO}_{2}$ and $\mathrm{CeO}_{2}+\mathrm{Dy}_{2} \mathrm{O}_{3}$ are obtained. As a results of films investigation by ellipsometry the dependencies of refraction and extinction coefficients on incident beam energy are presented. The dielectric permittivity and energy band gapes are calculated. The refraction coefficients of films $\mathrm{CeO}_{2}$ are 1.85-2.85 and are not more than 2.37 for complex films. Dielectric constant $\varepsilon$ of complex films are 3.57-4.16, and $\varepsilon=4.7$ of $\mathrm{CeO}_{2}$ film. The $\mathrm{CeO}_{2}, \mathrm{WO}_{3}$, and $\mathrm{WO}_{3}+\mathrm{CeO}_{2}$ films have wide band gape $E_{g}=2.8-3.37 \mathrm{eV}$.
\end{abstract}

Keywords: oxide high- $k$ materials, rare-earth elements, $\mathrm{CeO}_{2}$, optical characteristics, dielectric permittivity, and wide band gap.

Paper received 22.05.04; accepted for publication 21.10.04.

\section{Introduction}

The ways of microelectronics development are based on a permanent decrease in integrated circuit component dimensions. For metal-oxide semiconductor field effect transistors (MOSFET), first of all, the gate length should be reduced, which consequently results in scaling all others dimensions and is accompanied by appearance of new technological problems [1,2]. Because of the dimension decrease, which is related with, reduction of the dielectric thickness under the gate, there appear such problems as a drop of the breakdown voltage of this layer, increase in leakage current and operation voltage values. $\mathrm{SiO}_{2}$ is often used as a dielectric layer in silicon technology and certainly has excellent characteristics, namely: high quality of the interface between oxide silicon and silicon with density of surface traps $\sim 10^{10} \mathrm{~cm}^{-2} \mathrm{eV}^{-1}$, breakdown voltage is $15 \mathrm{MV} / \mathrm{cm}$, high thermodynamic and electrical properties stability. Even at $\mathrm{SiO}_{2}$ layer cutting down to $13 \AA$ MOSFET operates rather successful by [1]. However, at small thicknesses, there exist such undesirable effects as impurity penetration, especially boron from the high doped polysilicon gate. The problems of reliability stable and operation of transistor as well as undesirable leakage currents also appear. For example, in MOSFET with $\mathrm{SiO}_{2}$ thickness of $3.5 \mathrm{~nm}$ at the gate voltage of $1 \mathrm{~V}$ the leakage currents are $10^{-12} \mathrm{~A} / \mathrm{cm}^{2}$ and at the thickness $1.5 \mathrm{~nm}$ the leakage currents increase by 13 orders and reach $10 \mathrm{~A} / \mathrm{cm}^{2}$ [3]. For the normal operation of microprocessors and fast growing market of mobile phones and portable computers, there is strong demand to decrease the leakage current up to $\sim 10^{-3} \mathrm{~A} / \mathrm{cm}^{2}$ [1]. The problem solution of gate capacity keeping without the gate voltage increase can be provided by $\mathrm{SiO}_{2}$ layer change for dielectric having a higher value of the dielectric permittivity $\varepsilon$ and higher breakdown voltage. Certainly, this new dielectric should be compatible with silicon technology to form the high quality interface with silicon, to be thermodynamic and structurally stable and technologically reproducible. Nowadays, all over world the investigations aimed at the change of the silicon oxide are carried out. The favorites of investigations are [1]: $\mathrm{Ta}_{2} \mathrm{O}_{5}$, $\mathrm{SrTiO}_{3}, \mathrm{Al}_{2} \mathrm{O}_{3}, \mathrm{Ba}_{\mathrm{x}} \mathrm{Sr}_{1-\mathrm{x}} \mathrm{TiO}_{3}, \mathrm{~Pb}_{\mathrm{x}} \mathrm{Zr}_{1-\mathrm{x}} \mathrm{TiO}_{3}, \mathrm{Y}_{2} \mathrm{O}_{3}$, $\mathrm{La}_{2} \mathrm{O}_{3}, \mathrm{Pr}_{2} \mathrm{O}_{3}, \mathrm{TiO}_{2}, \mathrm{ZrO}_{2}$, and $\mathrm{HfO}_{2}$. But for all these materials, there is the problem of high quality interface with silicon formation. For the most cases, the density of trap states is $\sim 10^{12} \mathrm{~cm}^{-2} \mathrm{eV}^{-1}$.

One from perspective materials with the big $\varepsilon$ value is cerium dioxide $\mathrm{CeO}_{2}$ that can be deposited by different methods [4-9]. E.g., in the work [6] it was obtained the perfect quality of the interface $\mathrm{CeO}_{2} / \mathrm{Si}$ with the state density $6.8 \cdot 10^{10} \mathrm{eV}^{-1} \mathrm{~cm}^{-2}$ after annealing the deposited film 


\section{T.V. Semikina: Optical properties of dielectric layers with $\mathrm{CeO}_{2}$}

in oxygen at temperature $500^{\circ} \mathrm{C}$. Cerium dioxide was employed as a gate insulator for an enhancement-type nchannel metal-oxide semiconductor (MOS) transistor [10]. With $\mathrm{CeO}_{2}$ gate MOS device yielded an interface charge of $1.5 \cdot 10^{10} \mathrm{Coul} / \mathrm{cm}^{2}$ with threshold voltage of $0.3 \mathrm{~V}$. Because the threshold voltage was positive the $\mathrm{CeO}_{2}$ application rejected the problem of an additional processing step for charge reduction that exist for $\mathrm{SiO}_{2}$ dioxide. In the work [11], $\mathrm{CeO}_{2}$ film in the structure $\mathrm{CeO}_{2} / \mathrm{Ge}$ in MOSFET promoted the elimination of the native germanium oxide formation, which is an important result opposite to the case of usual uncontrolled native substrate oxide growth.

In this work, we propose the results of investigation of optical properties inherent to dielectric layers based on $\mathrm{CeO}_{2}$, namely: $\mathrm{CeO}_{2}, \mathrm{WO}_{3}, \mathrm{WO}_{3}+\mathrm{CeO}_{2}, \mathrm{CeO}_{2}+\mathrm{Dy}_{2} \mathrm{O}_{3}$ with the aim to get dielectric possessing a high $\varepsilon$ value. This class of materials was chosen as based on previous investigations of electrical properties that showed the possibility to get the high quality interface with silicon, where the density of surface traps was $\sim 10^{10} \mathrm{~cm}^{-2} \mathrm{eV}^{-1}$ [12] and breakdown voltage reached $3-3.2 \cdot 10^{6} \mathrm{~V} / \mathrm{cm}$. The obtained result of high quality interface is explained by small lattice mismatches between $\mathrm{CeO}_{2}$ and $\mathrm{Si}$. It is known [3] that binary oxide $\mathrm{CeO}_{2}$ has the high value of dielectric permittivity $\varepsilon=18 \ldots 26$ that allows to hope on increase in $\mathrm{CeO}_{2}$ films in comparison with silicon dioxide. Though it is known [1] that properties of thin films materials strongly differ from properties of volume materials and under thickness reduction the $\varepsilon$ value is also decreased. The incorporation of rare earth element Dy into the $\mathrm{CeO}_{2}$ film was fulfilled because Dy promotes the electric properties stabilization that is very important start to solve from the put problem for application of new dielectric material [1].

The optical properties were investigated by the methods of infrared (IR), Raman spectroscopy and ellipsometry. Infrared reflection spectra were measured at $20^{\circ}$ angle of incidence using a Bruker IFS 66 Fourier Transform Infrared Spectrometer based on the Michelson Interferometer. Raman spectra were excited using $\mathrm{Kr}^{+}$ Innova - 300 laser. Measurements were made using the, wave length $647.1 \mathrm{~nm}$, resolution achieved $2.5 \mathrm{~cm}^{-1}$, radiation power was $15 \mathrm{~mW}$. It was used nonpolarized radiation. The spectral analysis was performed by a Dilor XY 800 triple monochromator equipped with a Peltier cooled Wright CCD detector. Spectroscopic ellipsometry measurements were performed using a variable angle spectroscopic ellipsometer (VASE from J.A. Woollam Co., Inc.) equipped with a Xe-lamp source, single chamber monochromator, continuously rotating analyser and auto-retarder. The ellipsometric angles $\Psi$ and $\Delta$ were determined in the spectral range 0.8 to $5 \mathrm{eV}$ at $65^{\circ}, 70^{\circ}$ and $75^{\circ}$ angles of incidence. For data evaluation, the measured samples were described by a model taking into consideration the silicon substrate with an oxide layer on top, covered by the film containing $\mathrm{CeO}_{2}$ and an additional top layer consisting of 50\% film material and 50\% void material for modeling the surface roughness. For the silicon and $\mathrm{SiO}_{2}$, optical constants data base values were used. From the measured data, the thickness of the $\mathrm{SiO}_{2}$ film, thickness and roughness of $\mathrm{CeO}_{2}$ containing films and their optical constants were determined.

The standard X-ray diffractometr (Model DMAX-B, Rigaku, Tokyo, Japan) was used to determine the crystalline phases present in the samples. To identify compounds, we used JCPDF card files to match peak positions of possible $\mathrm{CeO}_{2}, \mathrm{WO}_{3}$ oxides.

\section{Technology of deposition}

All the experiments were performed using commercially available $p$-Si $(100)$ wafers $(\approx 440 \mu \mathrm{m})$ with a resistance of $4-10 \Omega \cdot \mathrm{cm}$, oxidized at temperatures about $940^{\circ} \mathrm{C}$ at atmospheric pressure in dry $\mathrm{O}_{2}$. Thin evaporated layers of $\mathrm{CeO}_{2}, \mathrm{WO}_{3}, \mathrm{WO}_{3}+\mathrm{CeO}_{2}, \mathrm{CeO}_{2}+\mathrm{Dy}_{2} \mathrm{O}_{3}$ were deposited by technology of flash evaporation from powder original materials onto the oxidized Si substrate. Before the deposition process, the substrates were cleaned in the solution:

$$
\text { 1 part } \mathrm{H}_{2} \mathrm{O}_{2}+1 \text { part } \mathrm{NH}_{4} \mathrm{OH}+4 \text { part } \mathrm{H}_{2} \mathrm{O}
$$

and then washed in deionised water for 10 minutes. These $\mathrm{Si}$ substrates with different thicknesses of $\mathrm{SiO}_{2}$ were used to check $\mathrm{SiO}_{2}$ thickness influence on properties of deposited films. The powder of $\mathrm{CeO}_{2}, \mathrm{WO}_{3}$ and couple $\mathrm{WO}_{3}+\mathrm{CeO}_{2}$ (the powder concentration of $\mathrm{CeO}_{2}$ was 10 , 15 and $20 \%$ of the common powder amount), $\mathrm{CeO}_{2}+\mathrm{Dy}_{2} \mathrm{O}_{3}$ (concentration $\mathrm{Dy}_{2} \mathrm{O}_{3}$ was $10,15,20 \%$ of the common powder amount) were used as material sources. The substrate temperature during the evaporation was $170 \ldots 180^{\circ} \mathrm{C}$. The chamber pressure was $10^{-5} \mathrm{~Pa}$. The light-doses of evaporated materials reached the tungsten filament with definite frequency supplied for the keeping of stoichiometric composition of double systems, evaporated and deposited onto the substrate with $\mathrm{SiO}_{2}$. $\mathrm{SiO}_{2}$ layers were used because the interface $\mathrm{SiO}_{2} / \mathrm{Si}$ has the highest quality. However, the $\mathrm{SiO}_{2}$ presence leads to reduction of the equivalent thickness of $\mathrm{CeO}_{2}+\mathrm{SiO}_{2}$ structure in comparison with the equivalent thickness of $\mathrm{CeO}_{2}$ film.

\section{Investigation of films chemical content}

The results of X-ray diffraction demonstrate that $\mathrm{CeO}_{2}$ films have sharp peaks of cerium dioxide in crystalline phase (Fig. 1). As is known [1], the polycrystalline films have higher $\varepsilon$ than the amorphous ones. However, the leakage current in polycrystalline films is also higher in comparison with that of the amorphous ones. Amorphous films are more homogeneous and better reproducible. Thus, it is more preferable to get amorphous films as gate dielectric in MOSFET, though the dependence on film structure and transistor operation is not studied well yet [1]. The task to prepare amorphous films based on $\mathrm{CeO}_{2}$ was solved by deposition of complex films $\mathrm{WO}_{3}+\mathrm{CeO}_{2}$. The films of pure $\mathrm{WO}_{3}$ possess an amorphous structure, 


\section{T.V. Semikina: Optical properties of dielectric layers with $\mathrm{CeO}_{2}$}

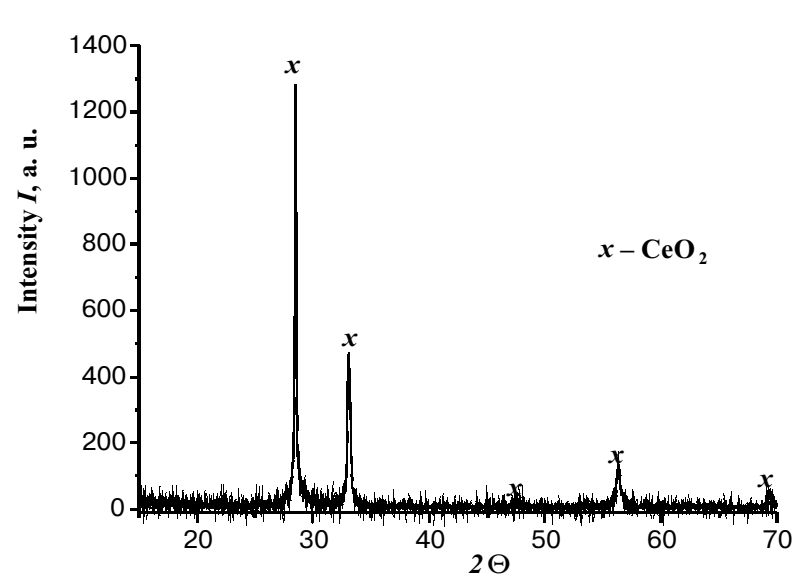

Fig. 1. X-ray diffraction spectrum of $\mathrm{CeO}_{2}$ film.

as it follows from X-ray diffraction results. It was obtained that after $\mathrm{CeO}_{2}$ introduction the resulting complex films $\mathrm{WO}_{3}+\mathrm{CeO}_{2}$ also possess the amorphous structure with impregnation of polycrystalline particles of $\mathrm{CeO}_{2}$.

\section{Results of Raman spectroscopy}

All Raman spectra of investigated materials have the same character and show neither the presence of peak at the wavelength $466 \mathrm{~cm}^{-1}$ typical for nanocrystalline $\mathrm{CeO}_{2}$ films [13] no others peaks. The only peak of silicon was present. From the obtained results, it can be concluded that the energy of exciting radiation at the wavelength $647.1 \mathrm{~nm}$ is not enough to excite vibrations, and hence studied materials have the wide bandgap.

\section{Results of infrared spectroscopy investigation}

From the IR reflection spectra of the researched materials (Fig. 2),it is seen that the deposited films have different thicknesses and deposited on the substrates with different thicknesses of native oxide. The samples with $\mathrm{CeO}_{2}$ films $(1,2,3)$ do not show the presence of $\mathrm{Si}-\mathrm{O}$ oxides in the films. Their spectral behaviour indicates that only a very thin native oxide layer is on the top of substrates. There were not the peaks indicative of the presence of vibrations inherent to $\mathrm{SiH}_{\mathrm{x}}$ and $\mathrm{Si}-\mathrm{OH}$ bonds and to water absorbed as free. The spectra of the samples with complex films $\mathrm{WO}_{3}+20 \% \mathrm{CeO}_{2}(7), \mathrm{CeO}_{2}+20 \% \mathrm{Dy}_{2} \mathrm{O}_{3}(9,10)$ and $\mathrm{CeO}_{2}+15 \% \mathrm{Dy}_{2} \mathrm{O}_{3}(8)$ show the presence of thick native oxide on the substrates ( $462 \mathrm{~nm}$ ). The strong feature at $1100 \mathrm{~cm}^{-1}$ (sample $\mathrm{WO}_{3}+20 \% \mathrm{CeO}_{2}, \mathrm{CeO}_{2}+15 \%$ $\mathrm{Dy}_{2} \mathrm{O}_{3}$ and $\mathrm{CeO}_{2}+20 \% \mathrm{Dy}_{2} \mathrm{O}_{3}$ ) and two weaker features at $466 \mathrm{~cm}^{-1}$ and $820 \mathrm{~cm}^{-1}$ are characteristic for $\mathrm{SiO}_{2}$. The weak peaks at 700 and $1600 \mathrm{~cm}^{-1}$ possibly concern with vibration modes of $\mathrm{CeO}_{2}$ element.

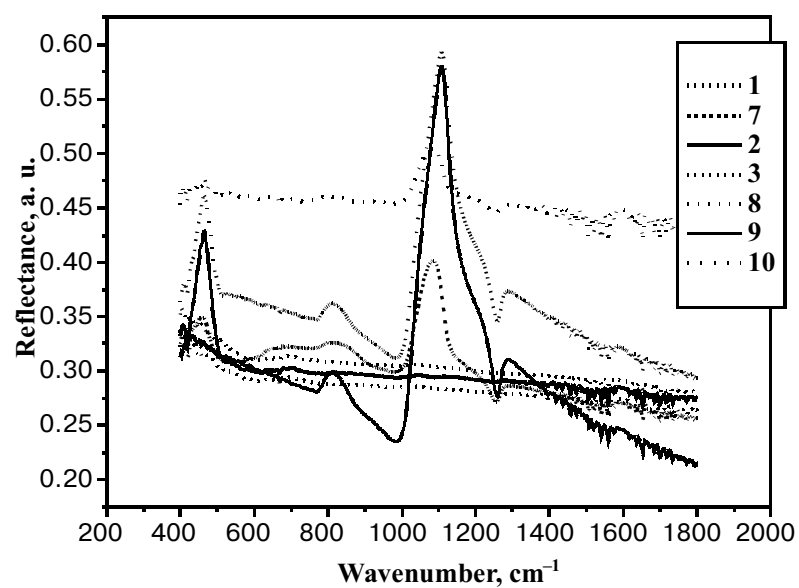

Fig. 2. IR-spectrums of the films: $1,2,3-\mathrm{CeO}_{2}, 7-\mathrm{WO}_{3}+20 \%$ $\mathrm{CeO}_{2}, 8-\mathrm{CeO}_{2}+15 \% \mathrm{Dy}_{2} \mathrm{O}_{3}, 9,10-\mathrm{CeO}_{2}+20 \% \mathrm{Dy}_{2} \mathrm{O}_{3}$.

The IR spectra of complex films $\mathrm{WO}_{3}+\mathrm{CeO}_{2}(5,6,7)$ at different cerium dioxide concentrations $(10,15,20 \%)$ and pure $\mathrm{WO}_{3}$ (4) film are presented in Fig. 3. It is seen that $\mathrm{CeO}_{2}$ introduction into $\mathrm{WO}_{3}$ film does not essentially change the original dependence character. Only for the sample with $\mathrm{CeO}_{2}$ content $10 \%$, the peaks near $1600 \mathrm{~cm}^{-1}$ become more intensive.

\section{Results of ellipsometry}

The film thickness and optical constants are determined by the ellipsometry method. There were used several simulation models applying point-by-point fit, model description of optical constants, and Kramers-Kronig consistent. It is obtained that the film thickness varies in the range $72-154 \mathrm{~nm}$ at the surface roughness of $5-12 \mathrm{~nm}$ (Table 1). $\mathrm{SiO}_{2}$ thickness is $6 \pm 1$ to $464 \pm 1 \mathrm{~nm}$, which is in a good agreement with results of IR spectroscopy.

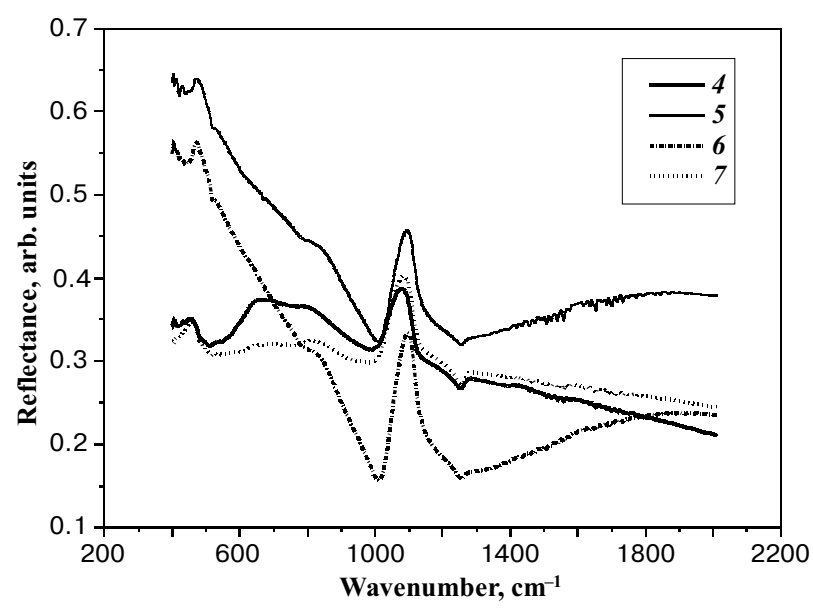

Fig. 3. IR-spectrums of the films: $4-\mathrm{WO}_{3}, 5-\mathrm{WO}_{3}+10 \% \mathrm{CeO}_{2}$, $6-\mathrm{WO}_{3}+15 \% \mathrm{CeO}_{2}, 7-\mathrm{WO}_{3}+20 \% \mathrm{CeO}_{2}$. 


\section{T.V. Semikina: Optical properties of dielectric layers with $\mathrm{CeO}_{2}$}

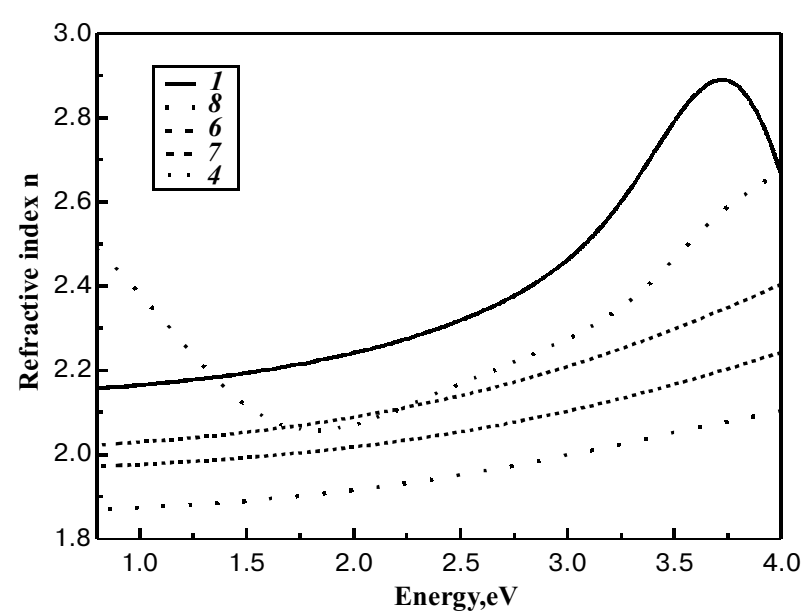

Fig. 4. Refractive coefficient dependence on photon energy for the films: $1-\mathrm{CeO}_{2}, 4-\mathrm{WO}_{3}, 6-\mathrm{WO}_{3}+15 \% \mathrm{CeO}_{2}, 7-\mathrm{WO}_{3}+20 \%$ $\mathrm{CeO}_{2}, 8-\mathrm{CeO}_{2}+15 \% \mathrm{Dy}_{2} \mathrm{O}_{3}$.

Under the usage of different simulation models for optical constant calculations it was obtained that the point-by-point approach gives more details for the character of refraction and extinction coefficients behavior having non-monotonic character with absorption spectrum broadening near the absorption edge. However, at this approach received is a plenty of noise signals, and parameters accuracy is $3-10 \%$ for different films because of big number of unknowns. The results of optical constants evaluation by the point-by-point and KramersKronig approaches are presented in Figs 4, 5 and Tab-

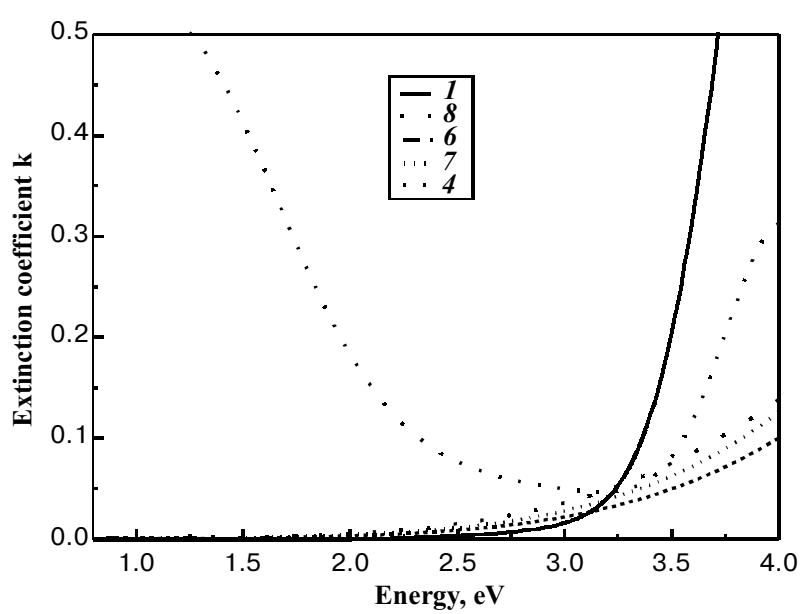

Fig. 5. Extinction coefficient dependence on photon energy for the films: $1-\mathrm{CeO}_{2}, 4-\mathrm{WO}_{3}, 6-\mathrm{WO}_{3}+15 \% \mathrm{CeO}_{2}, 7-\mathrm{WO}_{3}+20 \%$ $\mathrm{CeO}_{2}, 8-\mathrm{CeO}_{2}+15 \% \mathrm{Dy}_{2} \mathrm{O}_{3}$.

le 2. From Fig. 4 (Kramers-Kronig approach), it is seen that $\mathrm{CeO}_{2}$ refraction coefficient varies from 2.17 to 2.85 , which is a little bit higher than literature data (1.85-2.4) [14] and our previous results (2.2-2.4) [15]. This change of optical constants of complex $\mathrm{WO}_{3}+\mathrm{CeO}_{2}$ films do not depend on the cerium content in the film and dioxide silicon thickness.

On the base of obtained results of the point-by-point approach, it is plotted the dependence of wide bandgap $E_{g}$ on absorption coefficient $\alpha^{1 / 2}$ presented in Fig. 6(a-e). $\mathrm{WO}_{3}$ film has the biggest value $\varepsilon=5.76$ obtained by the

Table 1. The thickness of silicon dioxide and deposited films obtained by ellipsometry method.

\begin{tabular}{|l|l|c|c|c|}
\hline \hline \multirow{2}{*}{ Sample } & \multicolumn{3}{|c|}{ Thickness, nm } & \multirow{2}{*}{ Thickness non-uniformity } \\
\cline { 2 - 4 } & $\mathrm{SiO}_{2}$ & Film & Surface roughness & \\
\hline $\mathrm{WO}_{3}+15 \% \mathrm{CeO}_{2},(6)$ & $143 \pm 1$ & $72 \pm 1$ & $5 \pm 1$ & $<5$ \\
\hline $\mathrm{WO}_{3}+20 \% \mathrm{CeO}_{2},(7)$ & $144 \pm 1$ & $102 \pm 1$ & $6 \pm 1$ & $<4$ \\
\hline $\mathrm{CeO}_{2}+20 \% \mathrm{Dy}_{2} \mathrm{O}_{3},(9)$ & $464 \pm 1$ & $35 \pm 2$ & $7 \pm 1$ & $<3$ \\
\hline $\mathrm{CeO}_{2},(1)$ & $6 \pm 1$ & $154 \pm 1$ & $12 \pm 1$ & $<14$ \\
\hline $\mathrm{WO}_{3},(4)$ & $138 \pm 2$ & $116 \pm 1$ & $9 \pm 1$ & $<5$ \\
\hline
\end{tabular}

Table 2. The films optical constants and energy band gaps.

\begin{tabular}{|c|c|c|c|c|c|}
\hline \multirow[t]{2}{*}{ Sample } & \multicolumn{2}{|c|}{$n_{\min ,} h v=1.0 \mathrm{eV}$} & \multicolumn{2}{|c|}{$\varepsilon=n^{2}-k^{2}$} & \multirow{2}{*}{$\begin{array}{l}E_{g}, \mathrm{eV} \\
\text { Point-by- } \\
\text { point fit }\end{array}$} \\
\hline & $\begin{array}{l}\text { Point-by- } \\
\text { point fit }\end{array}$ & $\begin{array}{l}\text { Kramers- } \\
\text { Kronig model }\end{array}$ & $\begin{array}{l}\text { Point-by- } \\
\text { point fit }\end{array}$ & $\begin{array}{l}\text { Kramers- } \\
\text { Kronig model }\end{array}$ & \\
\hline $\mathrm{CeO}_{2}$ & 2.08 & 2.17 & 4.32 & 4.7 & 3.15 \\
\hline $\mathrm{WO}_{3}$ & 2.14 & 2.4 & 4.55 & 5.76 & 3.37 \\
\hline $\mathrm{WO}_{3}+\mathrm{CeO}_{2}(15 \%)$ & 2.0 & 1.98 & 4.0 & 3.92 & 2.8 \\
\hline $\mathrm{WO}_{3}+\mathrm{CeO}_{2}(20 \%)$ & 2.05 & 2.04 & 4.2 & 4.16 & 3.0 \\
\hline $\mathrm{CeO}_{2}+\mathrm{Dy}_{2} \mathrm{O}_{3}(20 \%)$ & 1.89 & 1.89 & 3.57 & 3.57 & 2.3 \\
\hline
\end{tabular}




\section{T.V. Semikina: Optical properties of dielectric layers with $\mathrm{CeO}_{2}$}
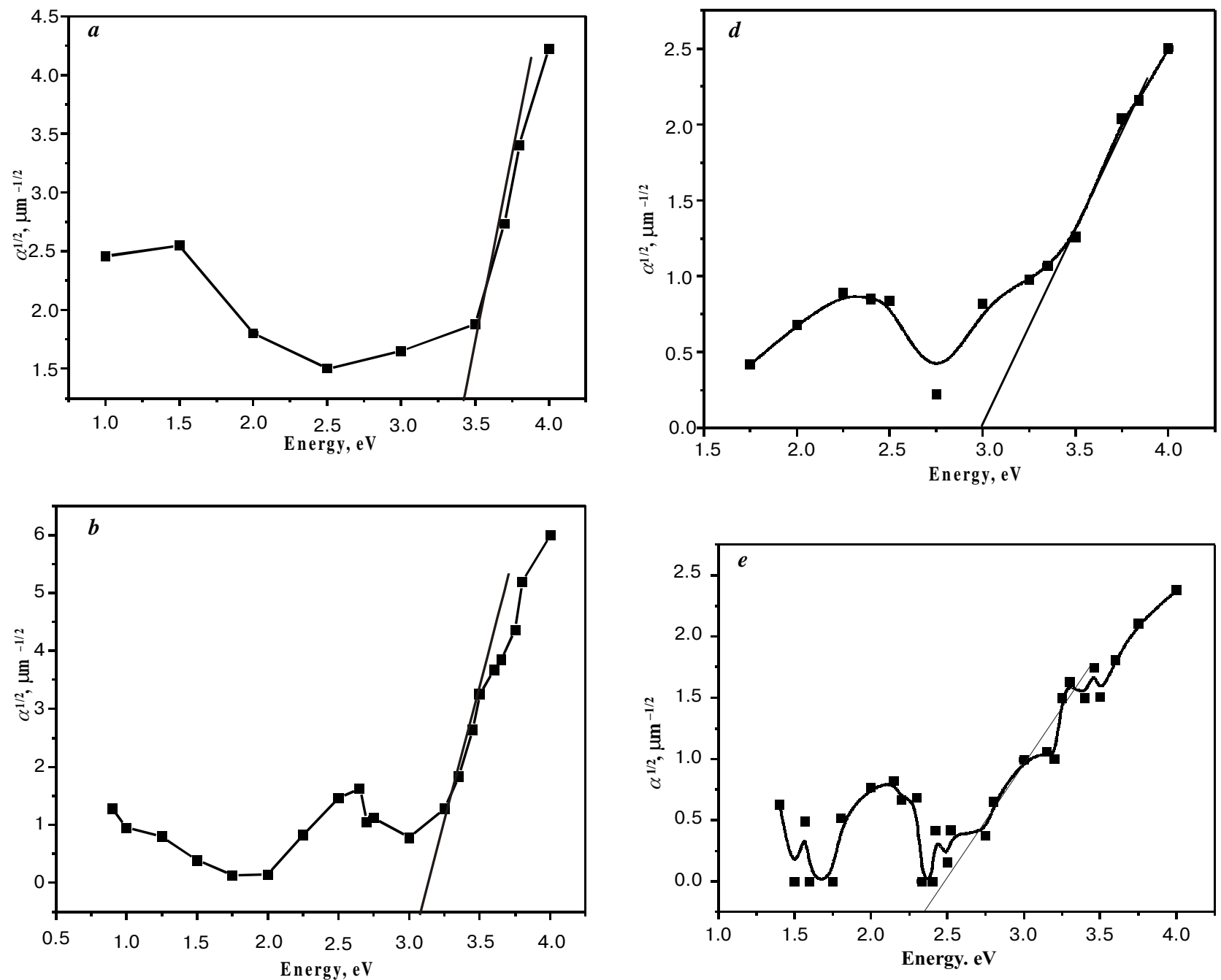

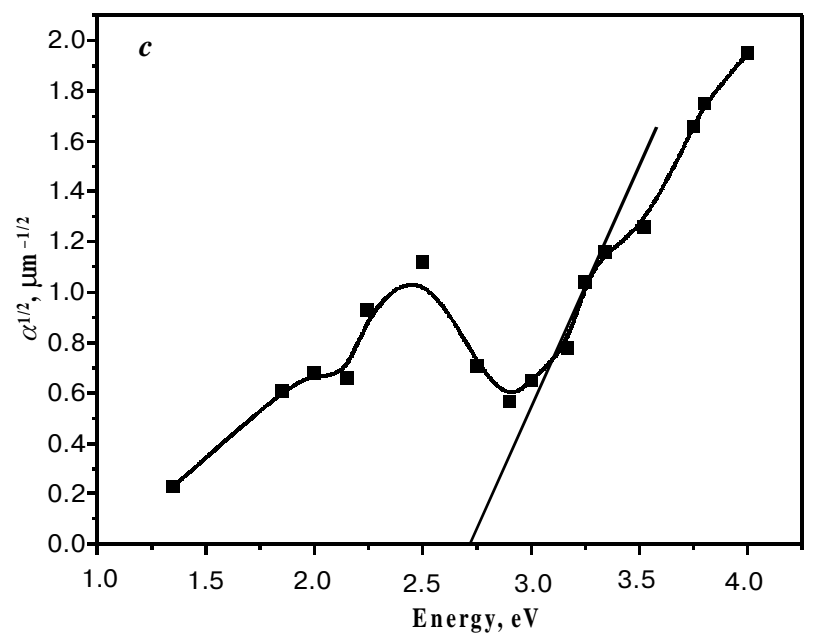

Fig. 6. Plot of the absorption coefficient $\alpha^{1 / 2}$ versus photon energy for different films: $a-\mathrm{WO}_{3} ; b-\mathrm{CeO}_{2}, c-\mathrm{WO}_{3}+\mathrm{CeO}_{2}(15 \%)$; $d-\mathrm{WO}_{3}+\mathrm{CeO}_{2}(20 \%) ; e-\mathrm{CeO}_{2}+\mathrm{Dy}_{2} \mathrm{O}_{3}(20 \%)$. The point of crossing of straight line and energy axis notes the energy band gap value.
Kramers-Kronig simulation. The $\varepsilon$ values 3.57-4.16 for complex films and $\varepsilon=4.7$ of $\mathrm{CeO}_{2}$ are not high enough to change for the gate dioxide silicon film $(\varepsilon=3.9)$.

The widths of bandgap (Table 2) are equal 2.3 to $3.37 \mathrm{eV}$. These data corresponds to literature data for $\mathrm{CeO}_{2}[16]$ where the bandgap for direct transition lies between 3.34 and $3.38 \mathrm{eV}$ and the bandgap for indirect transitions lies between 3.02 and $3.20 \mathrm{eV}$. Consequently, the $\mathrm{CeO}_{2}$ films, amorphous films $\mathrm{WO}_{3}$ and amorphous complex films $\mathrm{WO}_{3}+\mathrm{CeO}_{2}$ have the wide bandgap that is the necessary requirement to new gate dielectric.

\section{Conclusions}

As a result of fulfilled investigation, deposited are the polycrystalline thin films of $\mathrm{CeO}_{2}$, amorphous films $\mathrm{WO}_{3}$, amorphous complex films $\mathrm{WO}_{3}+\mathrm{CeO}_{2}$ and $\mathrm{CeO}_{2}+\mathrm{Dy}_{2} \mathrm{O}_{3}$. For the first time, the optical characteristics of complex films $\mathrm{WO}_{3}+\mathrm{CeO}_{2}$ and $\mathrm{CeO}_{2}+\mathrm{Dy} 2 \mathrm{O}_{3}$ are presented. The IR results are indicative of $\mathrm{SiO}_{2}$ presence in the films except for $\mathrm{CeO}_{2}$. Water in the films is not found. The refraction coefficient $(n=1.85-2.85)$ for $\mathrm{CeO}_{2}$ films is a little bit higher than that presented in literature data. 


\section{T.V. Semikina: Optical properties of dielectric layers with $\mathrm{CeO}_{2}$}

The $\mathrm{n}$ value of complex films is not more than 2.37. The calculated $\varepsilon=3.57-4.16$ of complex films and $\varepsilon=4.7$ of $\mathrm{CeO}_{2}$ do not allow to change for the gate dioxide silicon film. The deposited new films $\mathrm{CeO}_{2}, \mathrm{WO}_{3}$ and $\mathrm{WO}_{3}+\mathrm{CeO}_{2}$ have wide bandgap $E_{g}=2.8-3.37 \mathrm{eV}$.

To increase the dielectric permittivity $\varepsilon$, it is possible to introduce some changes into the technological process of film evaporation. For example, to carry out the evaporation in the environment of oxygen or nitrogen $\left(\mathrm{NH}_{3}\right.$, $\mathrm{N}_{2}$ ) with annealing treatment that, as is known $[6,17,18]$, leads to film defect reduction.

\section{Acknowledgment}

The author thanks A.N. Shmyryeva (NTUU "KPI") for the given samples and long time heading the authores work, V.G. Litovchenko for the consultation under results processing, Marion Friedrich and D.R.T. Zahn for the possibility to work in their laboratory of semiconductor physics in TU-Chemnitz, Germany. This work was financially supported by the grant from Ministry of Education of Saxon, Germany.

\section{References}

1. G.D. Wilk, R.M. Wallance, and J.M. Anthony, High-k gate dielectrics: Current status and material properties considerations // J. Appl. Phys., 89(10), pp. 5243-5275 (2001).

2. Int. Technology Roadmap for Semiconductors, http:// www.public.itrs.net.

3. Rainer Waser (editor), Silicon MOSFETs-Novel Materials and Alternative Concepts, Chap.13 in Nanoelectronics and Information Technology, Eds. Rainer Waser, pp. 361-385, Wiley-VCH, Weinheim, Germany, (2003).

4. T. Inoue, Y. Yamamoto, and M. Satoh, Low temperature epitaxial growth of $\mathrm{CeO}_{2}$ (110) layers on $\mathrm{Si}(100)$ using electron-beam assisted evaporation // Thin Solid Films, 343-344, pp. 594-597 (1999).

5. L. Kim, J. Kim, D. Jung, Ch.-Y. Park, Ch.-W. Yang, and Y. Roh, Effect of deposition parameters on the crystallinity of $\mathrm{CeO}_{2}$ thin films deposited on $\mathrm{Si}(100)$ substrates by r.f.magnetron sputtering // Thin Solid Films, 360, pp. 154-158 (2000).
6. H.W. Song, Ch. S. Lee, D.G. Kim, and K. No, Characterization of $\mathrm{CeO}_{2}$ thin films as insulator of metall ferroelectric insulator semiconductor (MFIS) structures // Thin Solid Films, 368, pp. 61-66 (2000).

7. S. Gnanarajan, and N. Sawides, Evolution of texture of $\mathrm{CeO}_{2}$ thin film buffer layers prepared by ion-assisted deposition // Thin Solid Films, 350, pp. 124-129 (1999).

8. B. Elidrissi, A. Addou, M. Regragui, C. Monty, A. Bougrine, and A. Kachouane, Structural and optical properties of $\mathrm{CeO}_{2}$ thin films prepared by spray pyrolysis // Thin Solid Films, 379, pp. 23-27 (2000).

9. B. Hirschauer, G. Chiaia, M. Goethelid, and U.O. Karlsson, Studies of highly oriented $\mathrm{CeO}_{2}$ films grown on $\mathrm{Si}$ (111) by pulsed laser deposition // Thin Solid Films, 348, pp. 3-7 (1999).

10. A.G. Frangoul, K.B. Sundaram, and P.F. Wahid, The fabrication of metal-oxide-semiconductors using cerium dioxide as a gate oxide material // J. Vac. Sci. Techol. B, 9(1), pp.181183 (1999).

11. D.P. Norton, J.D. Budai, and M.F. Chisholm, Hydrogenassisted pulsed-laser deposition of (001) $\mathrm{CeO}_{2}$ on (001) $\mathrm{Ge} / /$ Appl. Phys. Letters, 76(13), pp. 1677-1679 (2000).

12. A.N. Shmyryeva, V.V. Naumov, V.A. Kochelap, and T.V. Semikina, Inversion Solar Cell based on Silicon Structure with Cerium Oxide // World Renewable Energy Congress VII, 29 June-5 July, 2002, Cologne, Germany.

13. I. Kosacki, V. Petrovsky, and H.U. Anderson, Raman spectroscopy of nanocrystalline ceria and zirkonia thin films // $J$. Am. Ceram. Soc., 85(11), pp. 2646-2650 (2002).

14. K.B. Sundaram, P.F. Wahid, and P.J. Sisk, Characterization and optimization of cerium dioxide films deposited by r.f. magnetron sputtering // Thin Solid Films, 221, pp. 13-16 (1992).

15. O.V. Fursenko, T.V. Semikina, and A.N. Shmyryeva, Fabrication and ellipsometric investigation of thin films of rareearth oxides // Solid State Phenomena, 63-64, pp. 341-346 (1998).

16. K.B. Sundaram, and P. Wahid, Optical absorption in cerium dioxide thin films // Physica Status Solidi (b), 161, K63K66 (1990).

17. Seok-Woo Nam, Jung-Ho Yoo, Suheun Nam, Dae-Hong $\mathrm{Ko}$, Cheol-Woong Yang, and Ja-Hum Ku, Characteristics of $\mathrm{ZrO}_{2}$ films with $\mathrm{Al}$ and $\mathrm{Pt}$ gate electrodes // J. of The Electrochem. Soc., 150(12), G849-G853 (2003).

18. R. J. Carter, E. Cartier, A. Kerber, L. Pantisano, T. Schram, S. De Gendt, and M. Heyns, passivation and interface state density of $\mathrm{SiO}_{2} / \mathrm{HfO}_{2}$-based/polycrystalline-Si gate stacks // Appl. Phys. Letters, 83(3), pp.533-535 (2003). 